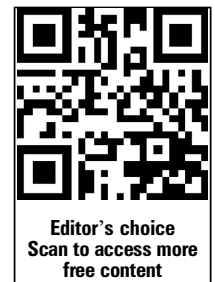

${ }^{1}$ AMIS Plus Data Center, Institute of Social and Preventive Medicine, University of Zurich, Zurich, Switzerland ${ }^{2}$ Division of Biostatistics, Institute of Social and Preventive Medicine, University of Zurich, Zurich, Switzerland ${ }^{3}$ Cardiovascular Department, Hôpital de La Tour, Geneva, Switzerland

${ }^{4}$ Division of Cardiology, Stadtspital Triemli, Zurich, Switzerland

${ }^{5}$ Division of Cardiology, Kantonsspital St. Gallen, St. Gallen, Switzerland ${ }^{6}$ Cardiology Centre, Klinik Im Park, Zurich, Switzerland ${ }^{7}$ Department of Cardiology, Luzerner Kantonsspital Luzern, Lucerne, Switzerland

\section{Correspondence to} Dr Dragana Radovanovic, AMIS Plus Data Center, Institute of Social and Preventive Medicine, University of Zurich, Hirschengraben 84 , Zurich 8001, Switzerland; dragana.radovanovic@uzh.ch

Published Online First 1 November 2013

\title{
Validity of Charlson Comorbidity Index in patients hospitalised with acute coronary syndrome. Insights from the nationwide AMIS Plus registry 2002-2012
}

\author{
Dragana Radovanovic, ${ }^{1}$ Burkhardt Seifert, ${ }^{2}$ Philip Urban, ${ }^{3}$ Franz R Eberli, ${ }^{4}$ \\ Hans Rickli, ${ }^{5}$ Osmund Bertel, ${ }^{6}$ Milo A Puhan, ${ }^{2}$ Paul Erne, ${ }^{7}$ on behalf of the \\ AMIS Plus Investigators
}

\begin{abstract}
Objective This study aimed to assess the impact of individual comorbid conditions as well as the weight assignment, predictive properties and discriminating power of the Charlson Comorbidity Index (CCI) on outcome in patients with acute coronary syndrome (ACS).

Methods A prospective multicentre observational study (AMIS Plus Registry) from 69 Swiss hospitals with 29620 ACS patients enrolled from 2002 to 2012. The main outcome measures were in-hospital and 1-year follow-up mortality.
\end{abstract}

Results Of the patients, $27 \%$ were female (age 72.1 \pm 12.6 years) and $73 \%$ were male (64.2 \pm 12.9 years). $46.8 \%$ had comorbidities and they were less likely to receive guideline-recommended drug therapy and reperfusion. Heart failure (adjusted OR 1.88; 95\% Cl 1.57 to 2.25$)$, metastatic tumours (OR $2.25 ; 95 \% \mathrm{Cl} 1.60$ to 3.19), renal diseases (OR 1.84; $95 \% \mathrm{Cl} 1.60$ to 2.11 ) and diabetes (OR 1.35; 95\% Cl 1.19 to 1.54) were strong predictors of in-hospital mortality. In this population, $\mathrm{CCl}$ weighted the history of prior myocardial infarction higher (1 instead of $-0.4,95 \% \mathrm{Cl}-1.2$ to 0.3 points) but heart failure (1 instead of $3.7,95 \% \mathrm{Cl} 2.6$ to 4.7 ) and renal disease (2 instead of $3.5,95 \% \mathrm{Cl} 2.7$ to 4.4 ) lower than the benchmark, where all comorbidities, age and gender were used as predictors. However, the model with $\mathrm{CCl}$ and age has an identical discrimination to this benchmark (areas under the receiver operating characteristic curves were both 0.76 ).

Conclusions Comorbidities greatly influenced clinical presentation, therapies received and the outcome of patients admitted with ACS. Heart failure, diabetes, renal disease or metastatic tumours had a major impact on mortality. $\mathrm{CCl}$ seems to be an appropriate prognostic indicator for in-hospital and 1-year outcomes in ACS patients.

ClinicalTrials.gov Identifier NCT01305785

\section{INTRODUCTION}

Chronic comorbidities are frequently encountered in patients presenting with acute coronary syndrome (ACS) and have a high impact on patient outcome. ${ }^{1-5}$ The Charlson Comorbidity Index (CCI) provides a way of quantifying this impact in terms of survival and is also used as a prognostic comorbidity index in ACS populations. ${ }^{6-10}$ Indices, such as CCI, are useful for estimating the prognosis of real-world patients with comorbidities. Although changes of management in ACS based on randomised controlled trials (RCT) have profoundly improved outcome, patients with comorbidities are still excluded from RCTs. ${ }^{6}$ To further improve treatment strategies, better knowledge of the impact of comorbidities is necessary. CCI may be an efficient way to capture the burden of comorbidities and study effect modification of current ACS treatments by comorbidities. ${ }^{11}$

CCI was developed empirically 26 years ago as a prognostic index of comorbid conditions for patients admitted to a general medical service with a variety of medical conditions which, alone or in combination, might alter the risk of short-term mortality for patients enrolled in longitudinal studies. ${ }^{12}$ The comorbidities were weighted by Charlson et al using a point system. One point was assigned to: past history of myocardial infarction (MI), heart failure, peripheral vascular disease, cerebrovascular disease, dementia, chronic lung disease, connective tissue disease, peptic ulcer disease, mild liver disease and diabetes. The comorbidities weighted with 2 points were: diabetes with target organ damage, hemiplegia, moderate to severe renal disease, malignant neoplasm, leukaemia and lymphoma. Moderate to severe liver disease was weighted with 3 points and metastatic solid tumour and AIDS (stage C) were weighted with 6 points. Therefore, patients without comorbidities had CCI0, those with only one comorbidity weighted as 1 had CCI1, patients with 2 comorbidities where both were weighted 1 or one comorbidity was weighted 2 had CCI2, and the patients in which the sum of the weighted points of comorbidities was 3 or above had CCI $\geq 3$.

Using the data of 55929 patients from six countries, Quan et $a l^{13}$ suggested that the weight assignment should be updated. However, CCI has not seen much validation in patients with ACS. Discrimination and calibration of CCI in ACS patients are not well known.

Therefore, the aim of this study was to assess the impact of CCI on clinical presentation, therapy received, the predictive properties of CCI in a large population of ACS patients and to see if changes of the CCI weight assignment are indeed necessary.

\section{METHODS}

The AMIS Plus project is an ongoing nationwide prospective registry of patients admitted with ACS to hospitals in Switzerland. It was founded in 1997
To cite: Radovanovic Heart 2014;100:288-294 
with the goal to understand the transfer, use and practicability of knowledge gained from randomised trials, and to generate data for the planning of subsequent prospective and randomised studies. Details have been previously published. ${ }^{14-18}$ From 106 hospitals treating ACS in Switzerland, 82 hospitals temporarily or continuously enrolled patients in AMIS Plus. Participating centres, ranging from community institutions to large tertiary facilities, provide blinded data for each patient through standardised internet-based or paper-based questionnaires. Participating centres are strongly encouraged to enrol all patients fulfilling the inclusion criteria to avoid selection bias. Hospital data are provided and completed by the treating physician or a trained study nurse. All data are checked for completeness, plausibility and consistency by the AMIS Plus Data Center in the Institute of Social and Preventive Medicine at the University of Zurich and treating physicians or study nurses are queried when necessary. The registry was approved by the Supra-Regional Ethics Committee for Clinical Studies, the Swiss Board for Data Security and the Cantonal Ethics Commissions. The AMIS Plus project is officially supported by the Swiss Societies of Cardiology, Internal Medicine and Intensive Care Medicine.

Comorbidities of the patients were assessed using CCI, ${ }^{12}$ a scoring system which involves weighting factors on the basis of the number and severity of the diseases that was developed as a prognostic indicator for patients admitted to a general medical service with a variety of medical conditions. CCI used 1-year mortality of the primary study population to test the ability to predict risk of death from comorbidities. It showed that with each increased level of CCI, there were stepwise increases in the cumulative mortality attributable to comorbidities. When CCI was developed, the relative risks for 1-year mortality were used to assign weights to the different comorbidities: Those with a relative risk below 1.5 were assigned a weight of 1 ; conditions with a risk of 1.5 to $<2.5$ a weight of 2 ; conditions with a risk of $\geq 2.5<3.5$ a weight of 3 ; and metastatic tumours and AIDS were assigned a weight of 6 . To simplify the system, the conditions with a relative risk below 1.2 were dropped. Finally, the relative risk per point was 1.39 . In a validation cohort, the ability of CCI for 10-year mortality was analysed. There, the relative risk was 2.3 per point of CCI and 2.4 for each decade of life over the age of 50 years. ${ }^{12}$

The original definitions of the comorbid diseases from CCI were used in this study. ${ }^{12}$ Data on the presence of the comorbidities were obtained from the patients' medical history charts, clinical and/or laboratory findings recorded by the treating physicians.

For the present analysis, the primary outcome measure was in-hospital mortality and the secondary outcome measure was 1-year mortality after discharge.

\section{Patient selection}

The present analysis included all ACS patients enrolled in AMIS Plus between January 2002 and September 2012. ACS included acute MI, defined according to the universal definitions of $\mathrm{MI}^{19}$ ${ }^{20}$ by characteristic symptoms and/or ECG changes and cardiac marker elevation (either creatine kinase $\mathrm{MB}$ fraction at least twice the upper limit of normal, or troponin I or T above individual hospital cut-off levels for $\mathrm{MI}$ ), and unstable angina (symptoms or ECG changes compatible with ACS and cardiac marker levels lower than cut-off or normal levels).

\section{Statistical analysis}

The results are presented as percentages for categorical variables, and continuous variables are expressed as means \pm 1 SD. The predictive properties of CCI were evaluated in three ways: First, a logistic regression model with in-hospital mortality as a dependent variable and the comorbidities of CCI, age and gender as independent variables were computed as the benchmark. Model fit of logistic regressions was assessed using the Hosmer-Lemeshow test. ORs were presented with 95\% CIs (95\% CI). AIDS could not be included in this analysis because there was no hospital death in patients with AIDS. To compare the results of this benchmark with the points of the CCI, the regression coefficients were scaled such that the sum is 31 . The benchmark points of a patient then are the sum of scaled regression coefficients of his comorbidities. A patient with all comorbidities would hence get 31 points as is the case for CCI. The points from this regression analysis are reported with $95 \%$ CI obtained by scaling the CI for the corresponding regression coefficient.

Second, a receiver operating characteristic (ROC) curve was used to assess the discriminating ability of CCI alone and together with age in relation to the benchmark above. Third, calibration of CCI was analysed by comparing predicted and observed in-hospital and follow-up mortality in a logistic regression with CCI and age as predictors. To assess sensitivity of the result, the analyses were repeated separately for patients with and without prior MI.

To assess CCI as an independent predictor of in-hospital mortality, an additional multivariate logistic regression analysis included, besides age and gender, Killip class, the type of ACS, drug therapies received (aspirin, P2Y12 blockers (clopidogrel, prasugrel, or ticagrelor), $\beta$ blocker, angiotensin-converting enzyme inhibitor (ACEI) or angiotensin receptor blocker (ARB), statin), and percutaneous coronary intervention.

All analyses were performed using IBM SPSS Statistics (V.20, SPSS, Chicago, Illinois, USA).

\section{RESULTS}

Between 2002 and 2012, 30711 patients with ACS from 69 Swiss hospitals were enrolled in the AMIS Plus registry. Comorbidities were unknown for 1091 (3.6\%) patients. Complete data on comorbidities were available from 29620 patients. Among these patients, 27\% were women (mean age $72.1 \pm 12.6$ years) and $73 \%$ were men $(64.2 \pm 12.9$ years), and $46.8 \%$ had comorbidities. The frequencies of comorbidities in ACS patients are shown in table 1. Past history of MI was the most frequent comorbidity $(18.0 \%)$ followed by diabetes mellitus $(14.7 \%)$, moderate to severe renal disease $(7.1 \%)$, cerebrovascular disease (6.0\%) and chronic lung disease (6.0\%).

More than half the patients $(53.2 \%)$ had no comorbidities (CCI0), $22.6 \%$ of the patients had comorbidities weighted with 1 point (CCI1), $11.3 \%$ with 2 points (CCI2), and $12.9 \%$ of the patients were weighted with 3 points and above $(\mathrm{CCI} \geq 3)$. Baseline characteristics and therapy according to CCI are shown in table 2.

\section{Impact of a single comorbidity on in-hospital mortality}

Table 3 shows the ORs of in-hospital mortality for the individual comorbidities. The strongest age and gender-adjusted predictors of in-hospital mortality for ACS patients were heart failure (adjusted OR 1.88 ; 95\% CI 1.57 to 2.25 ), metastatic tumours (OR 2.25; 95\% CI 1.60 to 3.19), renal diseases (OR 1.84; 95\% CI 1.60 to 2.11 ) and diabetes (OR 1.35 ; $95 \%$ CI 1.19 to 1.54 ).

\section{Impact of the weighted comorbidities on in-hospital mortality}

CCIs were independent in-hospital mortality predictors even after adjusting for baseline characteristics and the therapies 
Table 1 Frequency of the comorbidities in patients hospitalised with acute coronary syndrome between 2002 and 2012 ( $n=29$ 620)

\begin{tabular}{lcc}
\hline Comorbidities & $\begin{array}{l}\text { Number of } \\
\text { patients }\end{array}$ & $\begin{array}{l}\text { Percentage of } \\
\text { population }\end{array}$ \\
\hline Past history of myocardial infarction & 5324 & 18.0 \\
Heart failure & 1075 & 3.6 \\
Peripheral vascular disease & 1591 & 5.4 \\
Cerebrovascular disease & 1776 & 6.0 \\
Dementia & 582 & 2.0 \\
Chronic lung disease & 1778 & 6.0 \\
Connective tissue disease & 361 & 1.2 \\
Peptic ulcer disease & 665 & 2.2 \\
Mild liver disease & 227 & 0.8 \\
Diabetes & 4359 & 14.7 \\
Diabetes with target organ damage & 1069 & 3.6 \\
Hemiplegia & 210 & 0.7 \\
Moderate to severe renal disease & 2101 & 7.1 \\
Malignant neoplasm & 1269 & 4.3 \\
Leukaemia & 92 & 0.3 \\
Lymphoma & 139 & 0.5 \\
Moderate to severe liver disease & 170 & 0.6 \\
Metastatic solid tumour & 268 & 0.9 \\
AlDS (stage C) & 47 & 0.2 \\
\hline
\end{tabular}

received: CCI1 had an OR of 1.36 (95\% CI 1.16 to 1.60 ); $\mathrm{p}=0.001$, CCI2 was 1.65 (95\%CI 1.38 to 1.97$) ; \mathrm{p}<0.001$ and $\mathrm{CCI} \geq 3$ had an OR of 2.20 (95\% CI 1.86 to 2.57 ); $\mathrm{p}<0.001$.

The cause of in-hospital death was cardiac in 1238 (78.3\%) patients and non-cardiac in 344 (21.7\%) patients.

\section{Validity of $\mathrm{CCI}$}

ROC curve analysis (figure 1) demonstrates that predictive ability for in-hospital mortality of CCI together with age is superior to that of CCI alone. Age adjusted OR was 1.21 (95\% CI 1.18 to 1.23 ) per point of CCI. For each additional 10 years of age, the OR was 1.91 (95\% CI 1.82 to 2.00). Model fit was good (figure 2A) except for the patients below 50 years of age (Hosmer-Lemeshow $\mathrm{p}<0.001$ for all patients, and $\mathrm{p}=0.74$ for patients above 50 years of age).

CCI weighted the history of prior MI higher (1 instead of $-0.4,95 \% \mathrm{CI}-1.2$ to 0.3 points), but heart failure ( 1 instead of $3.7,95 \%$ CI 2.6 to 4.7 ) and renal disease (2 instead of 3.5 , $95 \%$ CI 2.7 to 4.4 ) lower than was the case with independent predictors for mortality. Comparing logistic regression using CCI and age as predictors with the benchmark from table 3, ROC analyses showed that the prediction was equivalent; the areas under the ROC curves were both 0.76 (figure 1).

Discrimination and model fit were similar for patients with and without prior MI-areas under the curve were 0.74 and 0.76 , and the $p$ values of the Hosmer-Lemeshow test for patients above 50 years of age were 0.37 and 0.95 , respectively.

\section{Impact of CCI on 1-year follow-up mortality}

Since 2005, a subgroup of 7066 ACS patients were followed for a median of 386 days (IQR 370, 409 days) after the event. From the followed patients, $57.7 \%$ had CCI0 (no comorbidities), $21.2 \%$ had CCI1, $10.5 \%$ CCI2 and 10.5\% CCI3 or above. Age adjusted OR was 1.44 (95\% CI 1.36 to 1.53 ) for follow-up mortality per CCI point. For each additional 10 years of age, the OR was 2.08 ( $95 \%$ CI 1.81 to 2.39 ). Area under the ROC curve was $0.83,95 \%$ CI 0.80 to 0.86 . Model fit was good (figure 2B, Hosmer-Lemeshow $\mathrm{p}=0.57$ ).

\section{DISCUSSION}

Our study showed that comorbidities, such as heart failure, diabetes, renal disease or metastatic tumours had a major impact on outcomes in patients hospitalised with ACS and confirmed previous studies that chronic comorbidities are frequently encountered in patients admitted for ACS in daily clinical practice.

The baseline characteristics of the ACS patients differed significantly between the CCI groups and in particular between those with no comorbidities (CCI0) and those patients with CCI1-CCI $\geq 3$, as clearly demonstrated by the risk factors hypertension, dyslipidemia and obesity. However, the proportion of current smokers was highest in the CCI0 group but steadily decreased the higher the weighted CCI. The higher the CCI, the longer the delay between symptom onset and admission, symptoms were less typical, there was a higher degree of haemodynamic instability (higher Killip class) and more frequent NSTEMI/UA compared with the patients with lower rates of comorbidities. ACS patients with comorbidities more frequently presented with cardiogenic shock, but were less frequently resuscitated before admission.

Furthermore, patients with comorbidities were less likely to receive guideline-recommended drugs (such as aspirin, P2Y12 blockers, $\beta$ blocker, ACEI/ARB or statin) within the first $24 \mathrm{~h}$ after admission, as well as reperfusion therapy especially in the case of STEMI patients. These results confirm the findings from an earlier study using AMIS Plus data. ${ }^{9}$

Most comorbidities included in CCI had a significant impact on outcome in this population. From 17 comorbid conditions, after adjusting for age and gender, nine were independent indicators of in-hospital mortality (heart failure, peripheral vascular disease, cerebrovascular disease, hemiplegia, diabetes, liver and renal diseases, malignant neoplasm and metastatic tumours; table 3). The strongest predictors of in-hospital mortality of ACS patients in our population were heart failure, metastatic tumours, renal diseases and diabetes. These results are in line with those reported by Palau et $a l^{21}$ who showed that renal disease and heart failure (besides dementia, peripheral artery disease and prior MI) were important comorbidities for ACS patients.

Our study showed CCI groups above zero were independent predictors of in-hospital mortality even after adjustment for the type of ACS and therapy received. In-hospital as well as 1-year follow-up mortality rose with increasing CCI scores.

The original CCI was based on the 1-year mortality from an inception cohort study of 604 patients admitted to a general medical centre during 1 month and tested for its ability to predict risk of in-hospital and 10-year mortality from comorbidity diseases in a second cohort of 685 patients treated for primary breast cancer. ${ }^{12}$ The results showed that among all the clinical and demographic variables, only two were significant predictors of risk of comorbid death-age and comorbidity. CCI was validated in several studies including patients with $\mathrm{AMI},{ }^{22}$ stable coronary artery disease, ${ }^{6}$ ischaemic stroke, ${ }^{7}$ as well as peritoneal dialysis patients ${ }^{8}$ and a Medicare population aged 65 years or older. ${ }^{23}$

The influence of CCI on in-hospital and 1-year follow-up mortality was lower, as was the case in the original work of Charlson et al. ${ }^{12}$

Comorbidities could have different impacts on all-cause mortality in patients depending on the main diagnosis leading to 
Table 2 Baseline characteristics and immediate therapy in patients admitted with acute coronary syndrome according to the Charlson Comorbidity Index

\begin{tabular}{|c|c|c|c|c|c|}
\hline & $\mathrm{CCl}=0$ & $\mathrm{CCl}=1$ & $\mathrm{CCl}=2$ & $\mathrm{CCl} \geq 3$ & $\mathrm{p}$ Values \\
\hline Patients, n (\%) & 15754 & 6708 & 3334 & 3824 & \\
\hline Male gender (\%) & $11896 / 15754(75.5)$ & $4815 / 6708(71.8)$ & $2237 / 3334(67.1)$ & $2638 / 13824(69.0)$ & $<0.001$ \\
\hline Mean age (SD), years & $62.3(12.9)$ & $67.9(12.6)$ & $72.2(11.9)$ & $74.9(10.9)$ & $<0.001$ \\
\hline History of CAD (\%) & $3194 / 15618(20.5)$ & $3437 / 6633(51.8)$ & $1843 / 3278(56.2)$ & $2451 / 3753(65.3)$ & $<0.001$ \\
\hline Hypertension (\%) & 7357/14 $969(49.1)$ & $4515 / 6378(70.8)$ & $2475 / 3181(77.8)$ & $3009 / 3664(82.1)$ & $<0.001$ \\
\hline Dyslipidemia (\%) & 7064/13998 (50.5) & $3823 / 5929(64.5)$ & 1923/2926 (65.7) & $2155 / 3283(65.6)$ & $<0.001$ \\
\hline Smoking (current) (\%) & $6579 / 14760(44.6)$ & 2035/6106 (33.3) & 789/2956 (26.7) & $801 / 3316(24.2)$ & $<0.001$ \\
\hline Obesity $\left(\mathrm{BMI} \geq 30 \mathrm{~kg} / \mathrm{m}^{2}\right)(\%)$ & $2457 / 13509(18.2)$ & $1308 / 5622(23.3)$ & $642 / 2766(23.2)$ & $709 / 3127(22.7)$ & $<0.001$ \\
\hline Time between symptom onset and admission in min (IQR 25 to 75) & $215(108,610)$ & $225(110,620)$ & $233(119,669)$ & $265(120,730)$ & $<0.001$ \\
\hline Resuscitation prior to admission (\%) & $689 / 15649(4.5)$ & 265/6679 (3.8) & 117/3351 (3.5) & $118 / 3800(3.1)$ & $<0.001$ \\
\hline \multicolumn{6}{|l|}{ Clinical presentation } \\
\hline Typical symptoms (\%) & $10416 / 11790$ (88.3) & $4148 / 4870(85.2)$ & 1997/2459 (81.2) & $\begin{array}{l}2130 / 2851 \\
(74.7)\end{array}$ & $<0.001$ \\
\hline Chest pain (\%) & 13 356/15 406 (86.7) & $5421 / 6550(82.8)$ & $2606 / 3217(81.0)$ & $2757(74.3)$ & $<0.001$ \\
\hline Dyspnea (\%) & $3279 / 14349$ (22.9) & 1925/6139 (31.4) & $1166 / 3047(38.3)$ & $1733 / 3560(48.7)$ & $<0.001$ \\
\hline Killip class ( $\mathrm{n}$ patients) & 15671 & 6677 & 3318 & 3805 & $<0.001$ \\
\hline Killip class I (\%) & $13808(88.1)$ & $5286(79.2)$ & $2339(70.5)$ & $2202(57.9)$ & \\
\hline Killip class II (\%) & $1234(7.9)$ & $954(14.3)$ & $651(19.6)$ & $1058(27.8)$ & \\
\hline Killip class III (\%) & $236(1.5)$ & $233(3.5)$ & $213(6.4)$ & $388(10.2)$ & \\
\hline Killip class IV (\%) & $393(2.5)$ & $204(3.1)$ & $115(3.5)$ & $157(4.1)$ & \\
\hline ACS (n patients) & 15754 & 6708 & 3334 & 3824 & $<0.001$ \\
\hline STEMI (\%) & $9480(60.2)$ & $3453(51.5)$ & $1538(46.1)$ & $1690(44.2)$ & \\
\hline NSTEMI (\%) & $5443(34.5)$ & $2716(40.5)$ & $1519(45.6)$ & $1929(47.8)$ & \\
\hline UA (\%) & $831(5.3)$ & $539(8.0)$ & $277(8.3)$ & $305(8.0)$ & \\
\hline $\begin{array}{l}\text { Peak creatine kinase IU/L (mean) } \\
\text { median } \\
\text { (IQR } 25 \text { to } 75)\end{array}$ & $\begin{array}{l}1204 \\
767 \\
(247,1938)\end{array}$ & $\begin{array}{l}883 \\
479 \\
(171,1372)\end{array}$ & $\begin{array}{l}735 \\
400 \\
(154,1135)\end{array}$ & $\begin{array}{l}631 \\
360 \\
(144,946)\end{array}$ & $<0.001$ \\
\hline Multivessel diseases (\%) & $\begin{array}{l}5703 / 10683 \\
(53.4)\end{array}$ & $2755 / 4065(67.8)$ & $1248 / 1802(69.3)$ & $1272 / 1663(76.5)$ & $<0.001$ \\
\hline \multicolumn{6}{|l|}{ Immediate therapy } \\
\hline Aspirin (\%) & 15 219/15 705 (96.9) & 6292/6681 (94.2) & 3083/3321 (92.8) & 3369/3805 (88.5) & $<0.001$ \\
\hline P2Y12 blocker $(\%)^{*}$ & $12746 / 15669$ (81.3) & $5030 / 6662(75.5)$ & 2216/3307 (67.0) & 2245/3791 (59.2) & $<0.001$ \\
\hline GPIIb/Illa inhibitors (\%) & $5243 / 15438(34.0)$ & $1755 / 6581(26.7)$ & 699/3265 (21.4) & $\begin{array}{l}561 / 3745 \\
(15.0)\end{array}$ & $<0.001$ \\
\hline Heparinst (\%) & 13 979/15 639 (89.4) & $5734 / 6658(86.1)$ & 2799/3303 (84.7) & 3054/3791 (80.6) & $<0.001$ \\
\hline$\beta$ blocker (\%) & $10395 / 15571$ (66.8) & $4416 / 6631(66.6)$ & $2147 / 3304(65.0)$ & $2296 / 3779(60.8)$ & $<0.001$ \\
\hline Statin $(\%)$ & $\begin{array}{l}12 \text { 222/15 } 603 \\
(78.3)\end{array}$ & 4955/6645 (74.6) & 2333/3778 (64.6) & 2441/3778 (64.6) & $<0.001$ \\
\hline ACEI/ARB (\%) & 7841/15 $564(50.4)$ & $3583 / 6632(54.0)$ & $1839 / 3303(55.7)$ & $\begin{array}{l}2022 / 3786 \\
(53.4)\end{array}$ & $<0.001$ \\
\hline Any PCI (\%) & 13 241/15 752 (84.1) & $5047 / 6708(75.2)$ & $2145 / 3334(64.3)$ & 1874/3824 (49.0) & $<0.001$ \\
\hline Reperfusion in STEMI patients & 9480 & 3453 & 1538 & 1690 & \\
\hline Thrombolysis (\%) & $681(7.2)$ & $199(5.8)$ & $68(4.4)$ & $48(2.8)$ & $<0.001$ \\
\hline Primary PCI (\%) & 7496 (79.1) & $2434(70.5)$ & $928(60.3)$ & $794(47.0)$ & $<0.001$ \\
\hline
\end{tabular}

*P2Y12 blockers: clopidogrel, prasugrel or ticagrelor.

theparins, unfractionated heparin or low molecular weight heparin.

$\mathrm{ACEl}$, angiotensin-converting enzyme inhibitor; ACS, acute coronary syndrome; ARB, angiotensin receptor blocker; CAD, coronary artery disease; CCI, Charlson Comorbidity Index; BMI Body Mass Index; PCl, percutaneous coronary intervention.

hospital admission. Thus, despite a relative weight of 6 , AIDS had no impact on mortality in our patients. The original CCI includes diseases which are also reflected in the population being evaluated.

Some studies modified CCI accordingly, as in a study on stroke patients ${ }^{7}$ and stable coronary artery disease. ${ }^{6}$ Another study purported that CCI might not be appropriate when using administrative data. ${ }^{24}$

The results of this study using prospectively collected data are important because they not only show the impact of single comorbidities on in-hospital and 1 year outcomes in a large population in real life, but also how the weighted comorbidities of CCI influenced the therapies received and, consequently, the outcomes of ACS patients. Furthermore, the validation of CCI showed that CCI seems to be an appropriate prognostic indicator for in-hospital as well as 1-year outcomes in ACS patients.

\section{LIMITATIONS}

Our study should be interpreted in the context of the following limitations: First, the weaknesses of AMIS Plus are common to all registries. Participation in the AMIS Plus registry is voluntary, the number of hospitals varied over the years and might not, 
Table 3 Charlson weight of comorbidities and comorbidities as independent predictors of in-hospital mortality in patients hospitalised with acute coronary syndrome

\begin{tabular}{|c|c|c|c|}
\hline Comorbidities & $\begin{array}{l}\text { Charlson } \\
\text { weight (points) }\end{array}$ & $\begin{array}{l}\text { OR }(95 \% \mathrm{Cl}) \text { age and } \\
\text { gender-adjusted }\end{array}$ & $\begin{array}{l}p \\
\text { Values }\end{array}$ \\
\hline $\begin{array}{l}\text { Past history of } \\
\text { myocardial infarction }\end{array}$ & 1 & 0.93 (0.82 to 1.05$)$ & 0.25 \\
\hline Heart failure & 1 & 1.88 (1.57 to 2.25$)$ & $<0.001$ \\
\hline $\begin{array}{l}\text { Peripheral vascular } \\
\text { disease }\end{array}$ & 1 & 1.23 (1.03 to 1.48$)$ & 0.021 \\
\hline Cerebrovascular disease & 1 & 1.26 (1.06 to 1.50$)$ & 0.009 \\
\hline Dementia & 1 & 1.15 (0.90 to 1.47$)$ & 0.27 \\
\hline Chronic lung disease & 1 & 1.18 (0.99 to 1.41$)$ & 0.07 \\
\hline $\begin{array}{l}\text { Connective tissue } \\
\text { disease }\end{array}$ & 1 & 0.99 (0.64 to 1.51$)$ & 0.95 \\
\hline Peptic ulcer disease & 1 & 0.98 (0.73 to 1.31$)$ & 0.87 \\
\hline Mild liver disease & 1 & 1.72 (1.09 to 2.70$)$ & 0.019 \\
\hline Diabetes & 1 & 1.35 (1.19 to 1.54$)$ & $<0.001$ \\
\hline $\begin{array}{l}\text { Diabetes with target } \\
\text { organ damage }\end{array}$ & 2 & 1.28 (1.04 to 1.58$)$ & 0.019 \\
\hline Hemiplegia & 2 & 1.92 (1.28 to 5.87$)$ & 0.001 \\
\hline $\begin{array}{l}\text { Moderate to severe } \\
\text { renal disease }\end{array}$ & 2 & 1.84 (1.60 to 2.11$)$ & $<0.001$ \\
\hline Malignant neoplasm & 2 & 1.29 (1.06 to 1.57$)$ & 0.012 \\
\hline Leukaemia & 2 & 1.41 (0.69 to 2.88 ) & 0.34 \\
\hline Lymphoma & 2 & 0.75 (0.34 to 1.65$)$ & 0.48 \\
\hline $\begin{array}{l}\text { Moderate to severe liver } \\
\text { disease }\end{array}$ & 3 & 1.82 (1.12 to 2.95$)$ & 0.016 \\
\hline Metastatic solid tumour & 6 & 2.25 (1.60 to 3.19$)$ & $<0.001$ \\
\hline AIDS (stage C) & 6 & $\begin{array}{l}\text { None of the } 47 \\
\text { patients died }\end{array}$ & \\
\hline
\end{tabular}

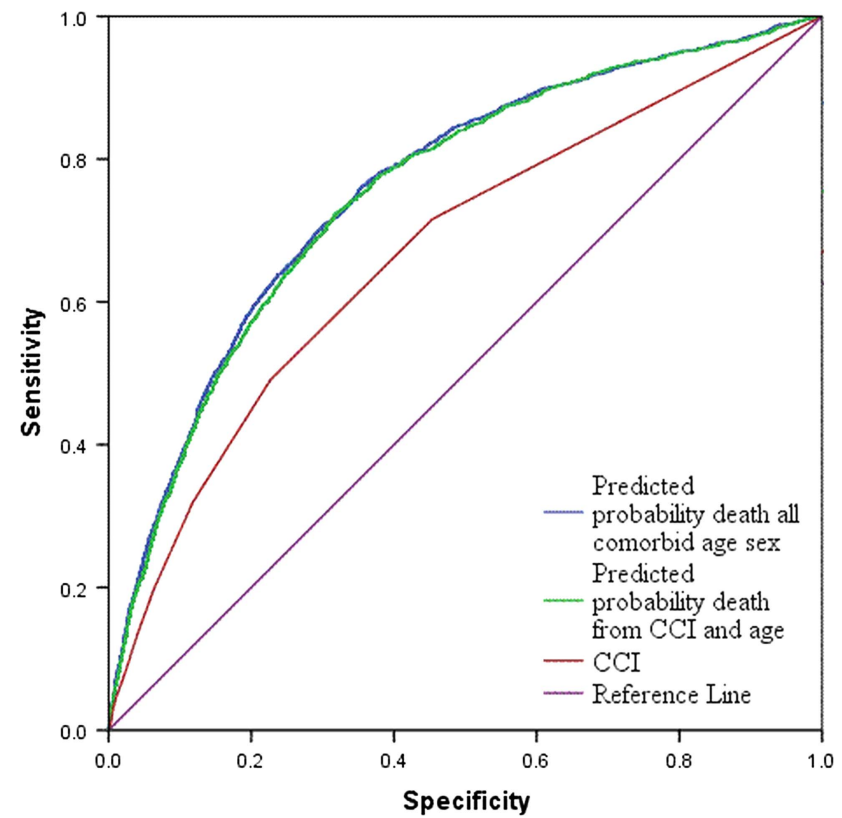

Figure 1 Receiver operating characteristic curve compared the discriminating ability of the Charlson Comorbidity Index (CCI) for predicting mortality if $\mathrm{CCl}$ was used alone (area $=0.670 ; 95 \% \mathrm{Cl} 0.656$ to 0.685 ), using $\mathrm{CCl}$ with age (area $=0.756 ; 95 \% \mathrm{Cl} 0.743$ to 0.768 ) and using all comorbidities, age and sex (area $=0.761 ; 95 \% \mathrm{Cl} 0.748$ to 0.773 ).
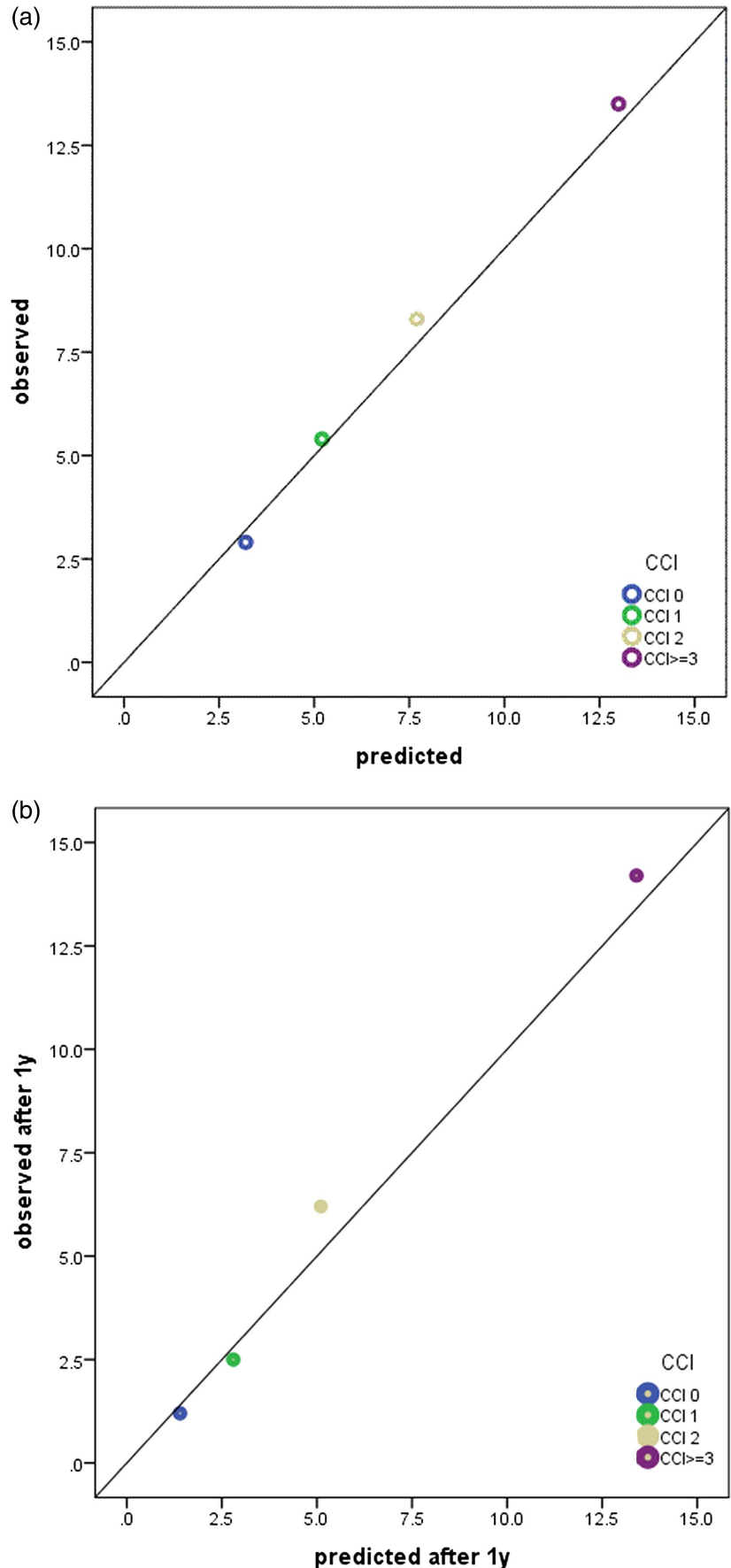

Figure 2 (A) In-hospital mortality compared with predicted mortality of patients admitted with acute coronary syndrome according to the Charlson Comorbidity Index (CCI) and age ( $n=29620)$. (B) 1-year follow-up mortality compared with the predicted mortality of patients admitted with acute coronary syndrome according to the $\mathrm{CCl}$ and age $(\mathrm{n}=7066)$.

therefore, be entirely representative for all-comers to all hospitals in the country despite the permanent involvement of more than $70 \%$ of all hospitals treating ACS. Second, there was not an independent valuation of the comorbidities. Also, in addition to chronic diseases, acute, non-cardiac conditions could be concomitant with acute MI, and greatly impact the outcome of these patients. ${ }^{25}$ Severe pneumonia, gastrointestinal bleeding, stroke and sepsis were associated with a marked increase in the risk of in-hospital mortality. ${ }^{25}$ These conditions are not defined precisely enough in the CCI. 
CCI was designed over 26 years ago, and although it has become the most widely used instrument to quantify chronic comorbidities for patients admitted to hospital for an acute major complaint, it was not designed specifically for patients with ACS. However, the present analysis is the largest multicentric study focusing on the importance of chronic comorbid conditions among patients admitted with ACS, and shows that despite all limitations, CCI could be a useful, simple and adequate tool in prospective ACS cohort studies.

\section{CONCLUSIONS}

Comorbidities greatly influenced clinical presentation and the therapies received by patients admitted with ACS, and have a major impact on the short-term and mid-term outcomes of these patients. In this study, heart failure, diabetes, renal disease and metastatic tumours had a major impact on mortality.

Furthermore, CCI seems to be an appropriate prognostic indicator for in-hospital as well as 1-year outcomes in ACS patients.

\section{Key messages}

\section{What is already known on this subject}

The Charlson Comorbidity Index (CCI) was empirically developed 26 years ago to provide a way of quantifying the impact of comorbidities on survival, and has been used as a prognostic tool in acute coronary syndrome (ACS) populations. However, the impact of comorbidities on the presentation and treatment of these patients is insufficiently known as there has been little validation of $\mathrm{CCl}$ in terms of patients with ACS.

\section{What this study adds}

The results of this study are important because they not only show the impact of single comorbidities on in-hospital and 1 -year-outcomes in a large real-life population, but also how the weighted comorbidities of $\mathrm{CCl}$ influence the therapies received, and consequently, the outcomes of ACS patients. Furthermore, this study shows that $\mathrm{CCl}$ indeed seems to be an appropriate prognostic indicator of in-hospital as well as 1-year outcomes in ACS patients.

Acknowledgements We gratefully thank our sponsors for their financial support. We also thank Jenny Piket for proofreading this manuscript.

Collaborators AMIS Plus participants 2002-2012: The authors would like to express their gratitude to the teams of the following hospitals (listed in alphabetical order with the names of the local principal investigators): Aarau, Kantonsspital (P Lessing); Affoltern am Albis, Bezirkspital (F Hess); Altdorf, Kantonsspital (R Simon); Altstätten, Kantonales Spital (PJ Hangartner); Baden, Kantonsspital (U Hufschmid); Basel, Universitätsspital Basel (P Hunziker/R Jeger); Basel, St. Claraspital (C Grädel/B Hornig); Bern, Beau-Site Klinik (A Schönfelder); Bern, Inselspital (S Windecker); Bern, Salem-Spital (T Rueff); Bern, Tiefenauspital (P Loretan); Biel, Spitalzentrum (H Schläpfer/C Roethlisberger); Brig-Glis, Oberwalliser Kreisspital (D Evéquoz); Bülach, Spital (G Mang), Burgdorf; Regionalspital Emmental (D Ryser); Davos, Spital (G Niedermaier/W Kistler); Dornach, Spital (A Droll/T Hongler); Einsiedeln, Regionalspital (S Stäuble); Flawil, Spital (G Freiwald); Frauenfeld, Kantonsspital (HP Schmid); Fribourg, Hôpital cantonal (JC Stauffer/S Cook); Frutigen, Spital (K Bietenhard); Genève, Hôpitaux universitaires (JM Gaspoz/ PF Keller); Glarus, Kantonsspital (W Wojtyna); Grenchen, Spital (B Oertli/R Schönenberger); Herisau, Kantonales Spital (M Schmidli); Horgen, See Spital (B Federspiel/D Schröpfer); Interlaken, Spital (EM Weiss); Kreuzlingen, Herzzentrum Bodensee (K Weber); La Chaux-de-Fonds, Hôpital (H Zender); Lachen, Regionalsspital (C Steffen/l Poepping); Langnau im Emmental, Regionalspital (A Hugi); Laufenburg, Gesundheitszentrum Fricktal (J Frei/E Koltai); Lugano, Cardiocentro Ticino (G Pedrazzini); Luzern, Kantonsspital (P Erne); Männedorf, Kreisspital (T Heimes); Mendrisio, Ospedale regionale (A Pagnamenta); Meyrin, Hôpital de la Tour (P Urban); Moutier, Hôpital du Jura bernois (C Stettler);
Münsingen, Regionales Spital Zentrum (F Repond); Münsterlingen, Kantonsspital (F Widmer); Muri, Kreisspital für das Freiamt (C Heimgartner); Nyon, Group. Hosp. Ouest lémanique (R Polikar); Olten, Kantonsspital (S Bassetti); Rheinfelden, Gesundheitszentrum Fricktal (HU Iselin); Rorschach, Kantonales Spital (M Giger); Samedan, Spital Oberengadin (P Egger); Sarnen, Kantonsspital Obwalden (T Kaeslin); Schaffhausen, Kantonsspital (R Frey/A Fischer); Schlieren, Spital Limmattal (T Herren/B Caduff); Schwyz, Spital (P Eichhorn); Scuol, Ospidal d'Engiadina Bassa (C Neumeier/G Flury); Sion, Hôpital du Valais (G Girod); Solothurn, Bürgerspital Solothurn (A Grêt/R Schönenberger/R Vogel); Stans, Kantonsspital Nidwalden (B Niggli); St. Gallen, Kantonsspital (H Rickli); Sursee, Luzerner Kantonsspital (S Yoon); Thun, Spital (U Stoller); Uster, Spital (E Bächli); Walenstadt, Kantonales Spital (D Schmidt/J Hellermann); Wetzikon, GZO Spital (M Graber/H Vontobel/U Eriksson); Winterthur, Kantonsspital (A Haller/T Fischer); Wolhusen, Luzerner Kantonsspital (M Peter); Zofingen, Spital (S Gasser): Zollikerberg, Spital (R Fatio); Zürich, Klinik im Park (O Bertel); Zürich, Universitätsspital Zürich (M Maggiorini); Zürich, Stadtspital Triemli (F Eberli); Zürich, Stadtspital Waid (M Fischler/S Christen/S Buchholz).

Contributors DR: conception and design, analysis and interpretation of data, drafting of the article. BS: analysis and interpretation of data, critical revision of manuscript. PU, FE, HR and OB: acquisition of data, critical revision of manuscript for intellectual content. MP: conception and design, critical revision of manuscript for intellectual content. PE: acquisition of data, conception and design, critical revision of manuscript for intellectual content.

Funding The AMIS Plus registry is funded by unrestricted grants from the Swiss Heart Foundation and from Abbot AG, Switzerland; Astra-Zeneca AG, Switzerland; Bayer (Schweiz) AG, Switzerland; Biotronik AG, Switzerland; Bristol-Myers Squibb AG, Switzerland; Daiichi-Sankyo/Lilly AG, Switzerland; Johnson \& Johnson AGCordis Division, Switzerland; A Menarini AG, Switzerland; Merck Sharp \& Dohme-Chibret AG, Switzerland; Medtronic AG, Switzerland; Pfizer AG, Switzerland; St. Jude Medical, Switzerland; Takeda Pharma AG, Switzerland. The sponsors did not play any role in the design, data collection, analysis, or interpretation of the registry.

\section{Competing interests None.}

\section{Patient consent Obtained.}

Ethics approval Supra-Regional Ethics Committee for Clinical Studies, the Swiss Board for Data Security and the Cantonal Ethics Commissions.

Provenance and peer review Not commissioned; externally peer reviewed.

\section{REFERENCES}

1 Alexander KP, Newby LK, Cannon CP, et al. Acute coronary care in the elderly, part I: Non-ST-segment-elevation acute coronary syndromes: a scientific statement for healthcare professionals from the American Heart Association Council on Clinical Cardiology: in collaboration with the Society of Geriatric Cardiology. Circulation 2007; 115:2549-69.

2 Alexander KP, Newby LK, Armstrong PW, et al. Acute coronary care in the elderly, part II: ST-segment-elevation myocardial infarction: a scientific statement for healthcare professionals from the American Heart Association Council on Clinical Cardiology: in collaboration with the Society of Geriatric Cardiology. Circulation 2007; 115:2570-89.

3 Boyd CM, Darer J, Boult C, et al. Clinical practice guidelines and quality of care for older patients with multiple comorbid diseases: implications for pay for performance. JAMA 2005;294:716-24.

4 Steg PG, Lopez-Sendon J, Lopez de Sa E, et al. External validity of clinical trials in acute myocardial infarction. Arch Intern Med 2007;167:68-73.

5 Tinetti ME, Bogardus ST Jr, Agostini JV. Potential pitfalls of disease-specific guidelines for patients with multiple conditions. N Engl J Med 2004;351:2870-4.

6 Sachdev M, Sun JL, Tsiatis AA, et al. The prognostic importance of comorbidity for mortality in patients with stable coronary artery disease. J Am Coll Cardiol 2004:43:576-82.

7 Goldstein LB, Samsa GP, Matchar DB, et al. Charlson Index comorbidity adjustment for ischemic stroke outcome studies. Stroke 2004;35:1941-5.

8 Fried L, Bernardini J, Piraino B. Charlson comorbidity index as a predictor of outcomes in incident peritoneal dialysis patients. Am J Kidney Dis 2001;37:337-42.

9 Fassa AA, Urban P, Radovanovic D, et al. Impact of comorbidities on clinical presentation, management and outcome of patients with acute coronary syndrome. Cardiovasc Med 2010;13:155-61.

10 Singh M, Rihal CS, Lennon RJ, et al. Influence of frailty and health status on outcomes in patients with coronary disease undergoing percutaneous revascularization. Circ Cardiovasc Qual Outcomes 2011;4:496-502.

11 Boyd CM, Vollenweider D, Puhan MA. Informing evidence-based decision-making for patients with comorbidity: availability of necessary information in clinical trials for chronic diseases. PLOS ONE 2012;7:e41601. 
12 Charlson ME, Pompei $\mathrm{P}$, Ales $\mathrm{KL}$, et al. A new method of classifying prognostic comorbidity in longitudinal studies: development and validation. J Chronic Dis 1987:40:373-83.

13 Quan H, Li B, Couris CM, et al. Updating and validating the Charlson comorbidity index and score for risk adjustment in hospital discharge abstracts using data from 6 countries. Am J Epidemiol 2011;173:676-82.

14 Jeger RV, Radovanovic D, Hunziker PR, et al. Ten-year trends in the incidence and treatment of cardiogenic shock. Ann Intern Med 2008;149:618-26.

15 Radovanovic D, Erne P. AMIS Plus: Swiss registry of acute coronary syndrome. Heart 2010;96:917-21.

16 Radovanovic $D$, Urban $P$, Simon $R$, et al. Outcome of patients with acute coronary syndrome in hospitals of different sizes. A report from the AMIS Plus Registry. Swiss Med Wkly 2010;140:314-22.

17 Schoenenberger AW, Radovanovic D, Stauffer JC, et al. Age-related differences in the use of guideline-recommended medical and interventional therapies for acute coronary syndromes: a cohort study. J Am Geriatr Soc 2008;56:510-16.

18 Stauffer JC, Goy JJ, Duvoisin N, et al. Dramatic effect of early clopidogrel administration in reducing mortality and MACE rates in ACS patients. Data from the Swiss registry AMIS-Plus. Swiss Med Wkly 2012;142:w13573.
19 Thygesen K, Alpert JP, White HD, et al. Universal definition of myocardial infarction. Eur Heart J 2007;28:2525-38.

20 Steg PG, James SK, Atar D, et al. ESC Guidelines for the management of acute myocardial infarction in patients presenting with ST-segment elevation. Eur Heart J 2012:33:2569-619.

21 Palau P, Nunez J, Sanchis J, et al. Differential prognostic effect of revascularization according to a simple comorbidity index in high-risk non-ST-segment elevation acute coronary syndrome. Clin Cardiol 2012;35:237-43.

22 Nunez JE, Nunez E, Facila L, et al. [Prognostic value of Charlson comorbidity index at 30 days and 1 year after acute myocardial infarction]. Rev Esp Cardiol 2004; $57: 842-9$.

23 Schneeweiss S, Wang PS, Avorn J, et al. Improved comorbidity adjustment for predicting mortality in Medicare populations. Health Serv Res 2003:38:1103-20.

24 Grunau GL, Sheps S, Goldner EM, et al. Specific comorbidity risk adjustment was a better predictor of 5 -year acute myocardial infarction mortality than general methods. J Clin Epidemiol 2006;59:274-80.

25 Lichtman JH, Spertus JA, Reid KJ, et al. Acute noncardiac conditions and in-hospital mortality in patients with acute myocardial infarction. Circulation 2007;116:1925-30. 